\title{
ETNICIDADE E AMBIENTE EM PROJETOS DE DESENVOLVIMENTO NO SUB-MÉDIO SÃO FRANCISCO
}

\author{
Parry $\operatorname{Scott}^{1}$ \\ https://orcid.org/0000-0003-2274-9859
}

\begin{abstract}
RESUMO
Este trabalho examina as práticas exercidas em relação à aplicação de licenciamento e compensação em ações da CHESF, no Sub-Médio São Francisco. Três experiências de envolvimento no processo, pelo autor, com inserções diferentes, orientam os realces dados a processos que são descritos de acordo com 1) definições de ambiente e etnicidade compreensíveis através das práticas da Empresa, e 2) a mobilização da população atingida na negociação de acordo com essas práticas. Examina o reassentamento de Itaparica, final dos anos oitenta; a elaboração de um EIA-RIMA para o projeto da barragem de Riacho Seco nos anos 2008-2009; e o cálculo de uma indenização para Povo Indígena Truká, em 2012. Foca nos usos e tensões entre as ideias de ambiente e etnicidade, ressaltando, nas conclusões, moralidade técnica, equipes multiprofissionais, história e políticas sociais, crescimento das universidades e as astúcias dos poderosos.
\end{abstract}

Palavras-chave: Etnicidade, Ambiente, Rio São Francisco, Antropologia.

\section{ETHNICITY AND ENVIRONMENT IN DEVELOPMENT PROJECTS IN THE SUB-MIDDLE SAN FRANCISCO RIVER}

\begin{abstract}
This article examines the practice of application of environmental licensing and compensation for acts done by the CHESF company in the Sub Middle San Francisco River. Three experiences of involvement of different kinds of involvement of the author in these processes are described according to 1) definitions of environment and ethnicity as understood by way of Company practices, and 2) the mobilization of the impacted population in negotiations that result from these practices. It examines the Itaparica resettlement in the end of the nineteen eighties, the elaboration of an Environmental Impact Assessment (EIA-RIMA) for the Riacho Seco dam Project in 2008-2009, and the calculation of an indeminization for the Truka Indigenous People in 2012. It focusses on the tensions between the ideas of ethnicity and environment. In the conclusions it emphasizes technical morality, multi-professional teams, history and social policy, the growth of the universities, and the astuteness of the powerful.
\end{abstract}

Keywords: Ethnicity, Environment, San Francisco River, Anthropology.

\section{ETNICIDAD Y AMBIENTE EN PROYECTOS DE DESARROLLO EN EL SUB-MEDIO RÍO SAN FRANCISCO}

\section{RESUMEN}

Este trabajo examina las prácticas de aplicación de licenciamiento y compensación en acciones de la CHESF en el Sub-Medio San Francisco. Tres experiencias de participación en el proceso por el autor con inserciones diferentes orientan los destaques dados a procesos descritos de acuerdo con 1) definiciones de ambiente y etnicidad comprensibles a través de las prácticas de la Empresa, y 2) la

\footnotetext{
${ }^{1}$ Doutor em Antropologia, University of Texas at Austin, 1981.Professor Titular Aposentado do Programa de PósGraduação em Antropologia, Departamento de Antropologia e Museologia. E-mail: rparryscott@gmail.com. Agradeço à Mércia Batista, Eliana de Barros Monteiro e Carla Siqueira Campos por contribuições valiosas na leitura de uma versão preliminar para MR. Movimentos Ambientais e Étnicos Diante de Políticas de Energia e Desenvolvimento, $32^{\mathrm{a}}$ Reunião Brasileira de Antropologia, UERJ - RJ, 2020.
} 
movilización de la populación impactada en la negociación de acuerdo con estas prácticas. Examina la relocalización de la populación de Itaparica, del final de los años ochenta; la elaboración de un EIA-RIMA para un proyecto de represa de Riacho Seco en los años 2008-2009, y el cálculo de una indemnización para el Pueblo Indígena Truká, en 2012. Enfatiza los usos y las tensiones entre las ideas de ambiente y etnicidad, llamando atención en las conclusiones a moralidad técnica, equipos multiprofisionales, historia y políticas sociales, crecimiento de las universidades, y las astucias de los poderosos.

Palabras clave: Etnicidad, Ambiente, San Francisco, Antropología.

\section{INTRODUÇÃO}

Quando o Ministério Público ou os gestores de um projeto de energia hidráulica chamam, ou são forçados a admitir, a presença de um antropólogo, é coisa certa que o projeto está danificando o meio ambiente e ameaçando comunidades de ribeirinhos, indígenas e/ou quilombolas. No ditado "aos amigos, tudo; aos inimigos, a lei" ${ }^{2}$, os antropólogos assumem, para os gestores, ser do grupo ao qual se aplica a lei. A criação de uma legislação mais rigorosa em defesa do ambiente e da população, no mínimo, aparenta proteger contra excessos de perdas, encarnada numa política de "mitigação". Mas, para os empreendimentos, essa legislação é, sobretudo, uma barreira a ser vencida para pôr em operação seu projeto de grande investimento $(\mathrm{GPI})^{3}$.

Nos relatos do Departamento de Ambiente do Banco Mundial, o antropólogo e assessor Michael Cernea (1991) reconhece o envolvimento pleno de antropólogos nas redes que criaram demandas para uma legislação ambiental rigorosa para GPIs, proveniente de denúncias de impactos nocivos nas pessoas e no ambiente em projetos observados, e pelas atitudes de protagonismo de causas ambientais e das pessoas. O incentivo mais intenso de legislação rigorosa no caso de GPIs ${ }^{4}$ veio da crítica ferrenha de uma equipe de antropólogos/sociólogos sobre as práticas dos gestores do projeto da barragem de Sobradinho, no Rio São Francisco, na Bahia (Machado, 1987; Sigaud 1986; Duque, 1982). A devastação do ambiente e a expulsão e empobrecimento da população que residia nas áreas atingidas com indenizações nulas ou irrisórias foram graficamente expostos. Demandas de reparação foram encaminhadas, criando tanto vexame para o Banco Mundial quanto ele é capaz de sentir sobre estes efeitos "secundários" dos seus planos de desenvolvimento. O Departamento de Ambiente desafiava a planificação de grandes investimentos no rol de atividades do Banco, cujo orgulho de promover desenvolvimento financeiramente ordenado servia como cartaz de legitimidade às ações do departamento de meio ambiente, encaixando-se nas relações públicas das suas atividades $(\text { Bronz 2013) })^{5}$.

\footnotetext{
${ }^{2}$ Em Maquiavel, a frase é "aos amigos, os favores; aos inimigos, a lei”.

${ }^{3}$ Estudiosos de ambiente e grandes empreendimentos documentam extensamente esta relação (ver considerações finais) nte de Políticas de Energia e Desenvolvimento.

${ }^{5}$ Bronz sobre publicidade e legitimação de práticas empresariais (Bronz, 2013).
} 
Inaugurada a barragem de Sobradinho, a próxima nas barragens planejadas pela CHESF foi a de Itaparica, jusante a Sobradinho, depois da qual vinha Xingó, Pedra Branca e Riacho Seco (ver Figura 1).

Figura 1 - Três projetos da CHESF com presença de antropólogos: Itaparica (1987), Riacho Seco (2008) e Ti Truká (2012)

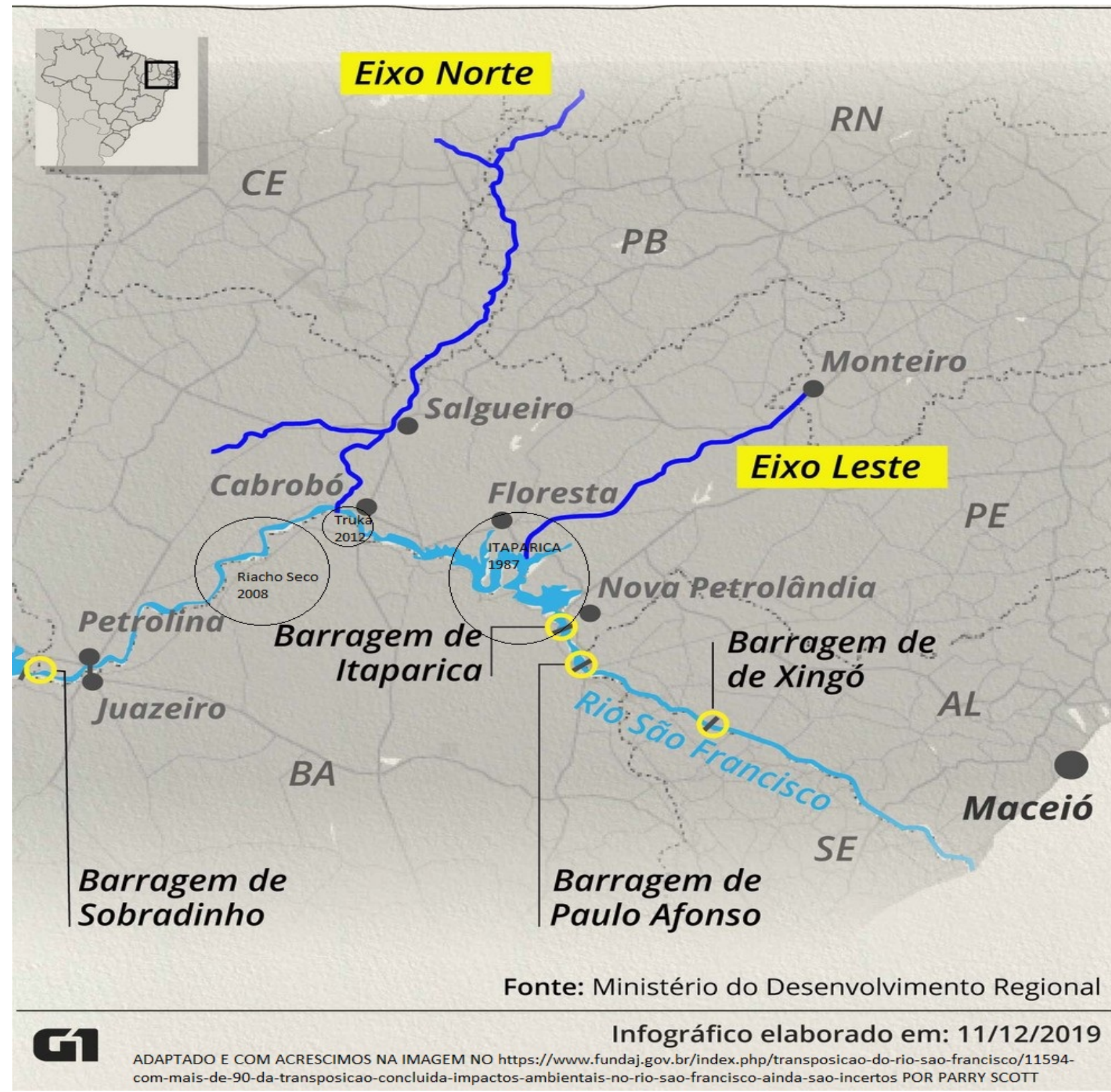

O planejamento empresarial energético se desenvolve por uma sucessão de tempos e espaços ao longo do rio. Os engenheiros do setor aproveitam o ambiente a partir do departamento específico de meio ambiente (veja https://www.chesf.gov.br/sustentabilidade/Pages/MeioAmbiente/MeioAmbienteVisaoGeral.aspx.). 
Na vez de Itaparica, intensificou-se muito significativamente a aplicação de novas legislações (Zhouri et al, 2005; World Bank, 1992; Barbieri 1995), com ferramentas para prever os danos (Environmental Impact Assessments - EIA) e, idealmente, escutar a população (audiências públicas que apresentam o Relatório de Impacto no Meio Ambiente - RIMA). Realizadas essas etapas do muito temido e frequentemente burlado licenciamento ambiental, os gestores têm "tudo" para levar os projetos adiante.

O RIMA costuma ser mais "apresentação" do que "escuta” e "discussão". Desde 1986, a resolução Número 01 do Conselho Nacional de Meio Ambiente-CONAMA (portanto historicamente depois das avaliações feitas em Itaparica), afirma que o RIMA é um:

relatório contendo as conclusões do EIA. Os dados devem ser apresentados de forma objetiva e adequada à compreensão pública. As informações devem ser traduzidas em linguagem acessível, ilustrados por meio de imagens, gráficos e tabelas de modo que se possam ser observadas as vantagens e desvantagens do projeto, bem como as consequências ambientais. (Acesso em www.inteliagro.com.br/qual-diferenca-entre-eia-e-o-rima/, 10 de junho de 2020).

É um passo obrigatório para o público. Não é deliberativo para o licenciamento, cabendo ao órgão governamental decidir sobre a aprovação. Como o EIA é de acesso restrito, a informação escrita para a população se restringe ao conteúdo do RIMA. Quando ficar tensionada, a audiência pode ser um importante incentivo para mobilização de resistência. Uma interpretação sociologicamente mais densa do EIA vê:

os estudos de impacto ambiental como dispositivos de governo que arregimentam certos tipos de expertise e poder para funcionar como mecanismos de visibilização e invisibilização" nos quais "a violência do Estado e dos agentes corporativos é naturalizada e rotinizada por meio de sua atividade administrativa. (Teixeira et. al. 2020, p. 7,13).

É neste quadro de referência que relato três experiências de acompanhar ações historicamente situadas de gestores nas quais a minha participação foi de ser um dos antropólogos em equipes chamadas para cumprir a legislação em intervenções pretendidas e realizadas ao longo do Rio São Francisco. O trabalho envolvia negociações complexas, dentro das próprias equipes, com os gestores, e com as populações impactadas. Aqui o realce é sobre os usos e articulações entre ambiente e identidade de populações, no conjunto das ações realizadas, criando um cenário complexo e às vezes contraditório de repertórios confrontacionais (Tilly, 2008) 6 .

Como a defesa de uma legislação mais rigorosa a favor das pessoas impactadas passa sempre por Departamentos de Ambiente, isso sinaliza que gestores se sentem mais à vontade lidando com o ambiente do que lidando com pessoas. Equipes de assistentes sociais e raros psicólogos se aglomeram

\footnotetext{
${ }^{6} \mathrm{O}$ uso da ideia de repertórios confrontacionais vem sendo empregado atualmente por Vânia Fialho e Whodson Silva, que estudam a resistência ao projeto de energia nuclear no município de Itacuruba, e agradeço a eles por sugerir a sua relevância para a área do sub-médio São Francisco.
} 
nesses departamentos. Criam ações subsidiárias à execução do projeto que obedecem aos ditames da modificação do ambiente proposta pelos setores de engenharia e execução, levando os funcionários nos setores mais "sociais" a viverem a incômoda dubiedade de simpatizar com os impactados, mas de ter que "vestir a camisa do projeto" e convencer a população de que, ou será beneficiada, ou será mitigada justamente, mesmo sem a instituição ter os meios ou objetivos prioritários de realizar tal façanha.

O caminho da resistência à implantação desses projetos que danificam o ambiente e a população envolve um agenciamento identitário de etnias e grupos sociais que estão no caminho dos projetos de desenvolvimento, articulados com uma aquinhoada consciência narrada do ambiente histórico onde residem e de uma articulação externa à instituição gestora do projeto nas diversas instâncias "de fricção" que compõem o processo, acionando variadas práticas nos seus repertórios confrontacionais. A instituição procede com o enquadramento destes elementos que ela chama de sociais (a palavra "étnicas" não costuma ser do seu agrado) através da sua predefinição preferencial que realça controle do ambiente (que parece ser mais controlável tecnicamente que o povo para ela).

Itaparica

A CHESF (Companhia Hidroelétrica do São Francisco) estava bem adiantada na construção da barragem de Itaparica quando, em 1987, elaborou termos de referência para uma "Avaliação do Reassentamento da População Rural de Itaparica" atingida pela barragem. Consultaram a Fundação Joaquim Nabuco (FUNDAJ) para acompanhar a ação durante 18 meses. Em obediência à legislação, alguns anos antes tinha contratado o estudo de salvamento arqueológico (Gabriela Martín Ávila, Marcos Albuquerque, arqueólogos da UFPE do Departamento de História). Na equipe, a antropóloga Judith Hoffnagel realizou levantamentos do patrimônio cultural existente das populações indígenas atuais na área a ser atingida, não havendo pedido para ver comunidades negras. O novo estudo do Reassentamento proposto seguiu orientações do financiador, o Banco Mundial, também em resposta às demandas legais. As coordenadas foram elaboradas por uma equipe internacional com forte contribuição do consultor antropólogo norte-americano, Daniel Gross, que trabalhou no Nordeste rural. ${ }^{7}$ O Brasil vivia na efervescência democrática da constituinte de 1988, acompanhado por brutais dificuldades no controle das altas taxas de inflação.

Na FUNDAJ, o chefe do Departamento de Economia, Dirceu Pessoa, perguntou ao professor Roberto Motta (antropólogo da FUNDAJ e da UFPE) se ele se interessava ou sabia de alguém que

\footnotetext{
$7 \mathrm{Na}$ página https://jornalggn.com.br/politicas-sociais/como-o-banco-mundial-quebrou-sua-promessa-de-proteger-ospobres/, acessado em 17 de junho de 2020, há o seguinte parágrafo: “Daniel Gross, um antropólogo que trabalhou como consultor e funcionário do banco durante duas décadas, conta que órgãos internos de fiscalização das salvaguardas têm "um lugar na mesa" nos debates sobre quanto a instituição deve fazer para proteger as pessoas. Mas, em meio ao esforço pela realização dos projetos, eles são frequentemente ignorados e pressionados para "jogar o jogo e cooperar".
} 
pudesse trabalhar junto com ele. O projeto exigia formalmente cocoordenação antropológica. Dirceu Pessoa $^{8}$, conhecedor exímio dos dilemas da seca do Nordeste e com sensibilidade e valorização de trabalho de campo e conhecimento antropológico, e eu elaboramos juntos um projeto de acordo com os termos de referência que orientaram dividir a área atingida em subáreas cujas histórias estavam marcadas por quatro diferentes sistemas locais de gerenciamento de águas, irrigação e trabalho em terras no entorno do rio que viraria lago. Com quase um ano até a previsão da abertura das comportas (Araújo et. al, 2000), o projeto permitiria acompanhar o processo de reassentamento da população com conhecimento das suas condições prévias de vida. Além de documentar o processo, acompanhávamos formalmente as mesas de negociações entre a equipe gestora da CHESF e o Polo Sindical do Sub-Médio São Francisco, representante ativo dos trabalhadores e agricultores da região. O Polo coordenava as confrontações arquitetadas pelos sindicatos rurais no conjunto dos municípios atingidos, em resistência à devastação dos seus espaços de vida e de trabalho. Além de passeatas e bloqueios de vias de transporte, o Polo havia paralisado a construção, ocupando o canteiro de obras por alguns dias para forçar definições claras e explícitas de recompensas e cálculos, numa ação bem documentada por movimentos populares e numa dissertação em sociologia (Pandolfi, 1986). A aprovação dos nossos relatórios sobre o processo de traslado e reassentamento era do próprio Departamento de Meio Ambiente (DMA) da CHESF, determinado pelos financiadores.

Sem esmiuçar a composição da equipe, é importante ressaltar detalhes que ilustram a complexidade interna do trabalho. Convidei a professora Maria Auxiliadora Ferraz de Sá para auxiliar como pesquisadora e supervisora de campo, antropóloga que focou relações de poder e o novo coronelismo na região (Sá, 1974), mestra em sociologia sob orientação de David Maybury-Lewis, antropólogo da Harvard University, pela cooperação com a Fundação Ford na institucionalização do Programa Integrado de Sociologia e Economia (PIMES), da UFPE. Não mantínhamos outros vínculos com a FUNDAJ ${ }^{9}$. Com o projeto aprovado, antes de iniciar o campo, Dirceu Pessoa assumiu a Secretaria Executiva do Ministério de Reforma Agrária e passou a cocoordenação para a socióloga mestra, Maria Lia Correia de Araújo (ex-Pandolfi), auxiliada por Rosa Amorim e funcionárias pesquisadoras Magda de Caldas Neto e Ana Elisa Lima. Ser diretor ou funcionário da FUNDAJ não permitia residir direto no campo, então foram alunos do curso de antropologia da UFPE que ficaram no campo e produziam diários e observações, contratados com remuneração mensal de mil dólares. No decorrer da pesquisa, a metodologia mudou, ocasionada pela aproximação da hora de enchimento do lago/reservatório e pela ampliação de custos dos pesquisadores decorrente da inflação e das dificuldades de administração de quatro residências alugadas em locais distintos no sertão, bem como

\footnotetext{
${ }^{8}$ Entre outras produções de Dirceu Pessoa, há A Seca Nordestina de 79-80. Fundação Joaquim Nabuco: Recife, 1983.

${ }^{9}$ Fiz curso de técnicas de pesquisa social em 1972 e fui estagiário doutorando em 1976-1978. 
pelo menor alinhamento da nova cocoordenação da equipe com as metodologias antropológicas iniciais. Suspenderam pesquisa etnográfica, substituindo-a por aplicação de questionários nos últimos meses, mais pessoal e tecnicamente controlável, geradora de mais informações quantitativas e que permitia estadas menores em campo. Na equipe multidisciplinar, com participação exigida de antropólogos, as condições de execução institucionais e disciplinares, sem ofuscar completamente o aporte do conhecimento antropológico, favoreceram um desfecho inclinado para a perspectiva sociológica.

Sobre as questões de ambiente e etnia e a sua relação com resistência a grandes projetos, quando a equipe FUNDAJ aceitou o convite da CHESF, não era somente a construção da barragem que estava em estado muito adiantado: um estudo de avaliação ambiental tinha sido feito. $\mathrm{O}$ cadastro de todos os impactados previstos também. $\mathrm{O}$ valor das benfeitorias tinha sido calculado, e uma grade de "escolhas" de reassentamento determinada, incluindo: 1) sete grandes projetos especiais de reassentamentos (especiais e na borda do lago) em complexos de agrovilas, dispersos em terras desapropriadas pelo sertão, para abrigar meeiros, posseiros e assalariado rurais (60\% da população); 2) soluções próprias (recebimento de indenização e autonomização do impactado - 10\%, principalmente com maiores patrimônios); e 3) vários projetos de grupos independentes impactados, negociados individualmente para se tornarem autônomos após remoção (Araújo et. al., 2000).

Com as terras férteis na beira do rio inundadas, a região seria tirada da sua condição de ter uma das maiores taxas de atividade econômica nos estados de Pernambuco e Bahia (apenas 3\% de desempregados). A ideia era de que nos novos locais se casaria a tecnologia de implantação e gestão de projetos irrigados, tão bem sucedida na região de Petrolina/Juazeiro pós-barragem de Sobradinho, e investiria em reassentamento em terras identificadas com condições edáfico-climáticas de suportar agricultura irrigada. Este processo criou novos atingidos entre os que residiam anteriormente nas terras destinadas aos projetos, expandindo o impacto da obra! Panfletos distribuídos para a população e interessados no projeto clamavam uma 'mudança para melhorar" com imagens semi-edênicas traçadas por arquitetos, pontuadas com gaivotas voando, fincadas num ideário de estarem criando pequenos empresários rurais e erradicando trabalho assalariado e de meação.

A gestão do ambiente dava margens a uma diferenciação social interna entre impactados. Tentava preservar pessoas da mesma comunidade juntos. A maioria seria indiferenciadamente identificada como "reassentados", potenciais pequenos empresários, em ambientes que operavam sob uma "moralidade técnica" regida pelo controle humano modernamente tecnologizado de fluxo de águas para organizar um plantio que antes dependia de variações sazonais de níveis e fluxos das águas do rio, que fertilizava as vazantes. A variação entre os grupos humanos reassentados (pouco percebidos como etnias nesse momento) seria homogeneizada como pequenos empresários rurais, orientados pelo relógio para a lavoura, e não pelas condições ambientais sentidas diariamente. Não 
foi um sucesso. O malgrado deste projeto de controle do e pelo ambiente combinava estudos apressados dos ambientes usando sensoriamento remoto com limitadas verificações locais terrestres sobre pedregosidade e salinização, assim como erros técnicos e atrasos na implementação dos sistemas de irrigação, alguns nunca chegando a produzir. A CODEVASF (Companhia de Desenvolvimento dos Vales do São Francisco e do Parnaíba) desistiu de receber os projetos de reassentados no quinto ano pós-reassentamento em razão desses erros técnicos, desautorizando os gestores consorciados e a CHESF enquanto administradores de projetos de irrigação. A resposta da CHESF, temendo a pecha na esfera de executores de GPIs de ter criado um projeto financeiramente pouco viável pelos altos custos "sociais" por reassentado, foi que a própria CHESF existe e tem alta competência para gerar energia, não para projetos de produção agrícola irrigada, que caberia à CODEVASF, sediada em Petrolina.

O projeto de acompanhamento tinha se baseado na diferenciação de sistemas produtivos e de gestão de água e de trabalho ao definir quatro subáreas de investigação, muito mais do que questões de etnicidade. Duas "complicações" étnicas tinham sido "resolvidas" administrativamente antes dos termos de referência: 1) o povo indígena Tuxá, cujo reassentamento estava sendo discutido junto à FUNAI e não pelo Polo Sindical, foi objeto de um estudo separado, associado ao nosso acompanhamento geral, realizado por Rita Melo (mestra em Antropologia da UFPE); 2) um grupo pequeno de indígenas que residiam em alguns espaços não administrativamente indígenas na beira do rio mudaram para Inajá, num projeto especial que deu reforço para a reemergência étnica do grupo Pipipã (Gonçalves et al, 2018). A proximidade dos Pankararu e a inundação das terras sagradas não foi diretamente trabalhada, mantendo uma área de conflito ignorada.

Mesmo havendo conhecimento da existência de grupos de "pretos" em diversos locais ao redor do reservatório, em especial em Itacuruba, não entraram no equacionamento de "populações diferenciadas" pelo reassentamento. O resultado foi fragmentação do povo indígena Tuxá, com um grupo nas proximidades do lago e outro a mil quilômetros em Ibotirama; o afastamento dos Pipipã residentes na área atingida; a manutenção de um conflito latente com os Pankararu; e um silêncio sobre a população negra "Negros de Gilu" dispersa, que voltou ao município de Itacuruba para conseguir reconhecimento como comunidade quilombola mais de uma década depois (Bezerra, 2007).

A negociação entre a CHESF e o Polo Sindical do Sub-Médio São Francisco articulou movimentos sociais nacionais e internacionais, agências humanitárias e de ajuda estrangeiras, a igreja progressista, ONGs e organizações sindicais em defesa dos direitos dos reassentados a uma compensação justa, sintetizada na reivindicação de "Terra por Terra na Borda do Lago". Sobre o ambiente, a equipe que negociava em nome da CHESF insistia que a sua escolha de ambientes mais distantes para os grandes projetos especiais de reassentamento obedecia a critérios técnicos de 
conhecimento de agrônomos de fertilidade do solo e potencial para produção. Apresentavam a sua argumentação como melhor informada ambientalmente do que os argumentos dos associados ao Polo Sindical que queriam seguir a orientação de receber "terras inférteis, imprestáveis para agricultura", na "borda do lago".

A liderança do Polo Sindical esclareceu que os Sindicatos não tinham condições de contar com indígenas nas suas reivindicações, por esses grupos disporem da invejável condição de ter uma entidade governamental para representá- $\operatorname{los}^{10}$. Os agricultores e trabalhadores no sindicato localmente se dividiam entre as categorias de trabalhadores rurais, meeiros, pequenos proprietários e posseiros. A hostilidade à negociação que reconhecia identidade étnica se explica, ao constatar que alguns posseiros na liderança do sindicato têm terras, das mais férteis, dentro do Território Indígena Pankararu, disputando abertamente sobre o domínio dessas terras.

Finalizado o acompanhamento do reassentamento com fortes conclusões sobre ajustes necessários, nos próximos anos nossos pesquisadores se envolveram em diversos projetos junto ao Polo Sindical no reforço do protagonismo dos direitos dos reassentados. Os gestores da CHESF, em mais de uma ocasião, falavam que o trabalho de antropologia era do "inimigo que nos critica, o que é uma necessidade". Mistura alinhamento e desalinhamento em tensa convivência, aquilo que a antropóloga Anna Tsing (2004) denomina de "fricção" como fundamental para as coisas andarem! ${ }^{11}$ Nas conclusões deste trabalho, é discutida a relação das condições do reassentamento de Itaparica com experiências em duas outras articulações, em outras datas, entre ambiente e etnia: Riacho Seco e a Ilha de Assunção.

\section{Riacho Seco}

Depois de duas décadas, em 2008, a conjuntura histórica tinha aberto para políticas de cidadania indígena e negra, com reconhecimento de territórios indígenas e comunidades quilombolas por instâncias governamentais e uma expressiva e visível (re)emergência étnica (Oliveira-Filho, 1999). Grupos étnicos, frequentemente atingidos por projetos de governos anteriores e atuais que enfatizavam aceleração de crescimento, se articularam com setores favoráveis ao seu reforço em esferas governamentais e não governamentais. Criaram Programas de Educação Intercultural Superior, fundamentadas na LDB 9.394, de 1996, incluindo a elaboração de material didático etnicamente específico para os níveis educacionais fundamental e médio. Estabeleceram políticas específicas de saúde indígena. Formaram museus indígenas interativos com a comunidade local e gestados por indígenas. A Fundação Cultural Palmares, criada para reforçar identidades culturais

\footnotetext{
${ }^{10}$ Os resultados para os indígenas desmentem a vantagem da presença de uma instituição governamental especificamente voltada para eles.

${ }^{11}$ Tsing é evocada na tese na UFPE, por Grimaldi (2013), para ajudar na interpretação das práticas de liderança do Povo Tumbalala, cujo território foi ocupado por um projeto especial da CHESF.
} 
diversas desde a Constituição de 1988, saía do relativo anonimato, aliando-se com objetivos do movimento negro e reconhecendo comunidades quilombolas. O INCRA elaborou gestão fundiária coletiva para reforçar a governança da identidade coletiva pelo caminho duplo de "regularização" e de "gestão" territorial. Mesmo com retrocessos e confrontações, expulsão de posseiros, retomadas e outras ações de protagonismo étnico, grupos indígenas e quilombolas conseguiam ser reconhecidos e alguns demarcaram seus Territórios. Coadunado com este processo, o Ministério de Desenvolvimento Agrário desenvolveu o Programa de Igualdade de Gênero, Raça e Etnia (PPIGRE) voltado para mulheres rurais ${ }^{12}$. Havia bastante sintonia entre as Secretarias de Promoção de Equidade e Igualdade de Raça (SEPPIR) com a Secretaria Nacional das Mulheres (SPM) e políticas associadas à raça, etnia e gênero.

A legislação ambiental tinha se consolidado, exigindo mais rigor em Estudos de Impacto Ambiental (Barbieri, 2004). Incluía comunidades ribeirinhas, negras e indígenas (sob a categoria de "comunidades tradicionais" - etnicizados ou não) ${ }^{13}$. Ganhando espaços Institucionalizados no governo, além dos indígenas e a atuação da FUNAI, somaram-se os esforços da SEPPIR e a Fundação Cultural Palmares, para favorecer aspectos étnicos dos seus pertencimentos. A aplicação de políticas sociais (sobretudo de transferência de renda) aumentou a interação direta e legitimada destas populações, de instituições do governo, de organizações não-governamentais e de pesquisa.

A SEPPIR (Secretaria de Políticas de Promoção da Igualdade Racial), instituída em 2003 pelo Presidente Lula, de acordo com a Convenção 169 da OIT, assinada pelo Brasil em 1989, descreve a ideia de uma política de povos tradicionais na página http://www.justica.pr.gov.br/Pagina/Povos-eComunidades-Tradicionais (acessado em 16 de junho de 2020):

No Brasil, esse público passou a integrar a agenda do governo federal em 2007, por meio do Decreto 6040, que instituiu a Política Nacional de Desenvolvimento Sustentável dos Povos e Comunidades Tradicionais (PNPCT), sob a coordenação da Secretaria de Políticas de Promoção da Igualdade Racial (SEPPIR) da Presidência da República.

A antropologia da UFPE havia crescido em professores dedicados a estudos étnicos com a inclusão do NEPE (Núcleo de Estudos e Pesquisas de Etnicidade), professores Renato Athias, Vânia Fialho, Peter Schröder, Frei Tito (Bartolomeu de Medeiros). Também contava com a presença da professora Salete Cavalcanti, autora de um dos primeiros estudos etnográficos de comunidades negras no Nordeste (Talhado, dissertação no Museu Nacional, em 1975). Via NEPE, muitos discentes foram incorporados no fortalecimento da auto-gestão de Associações Indígenas, de programas de atenção à

\footnotetext{
${ }^{12}$ Sob a coordenação de Andrea Butto Zarzar, então mestra egressa de antropologia da UFPE.

${ }^{13}$ Carla Siqueira, em nota particular, realça que desde o tempo do EIA de Riacho Seco, a forma de tratar esta questão vai mudando. Atualmente existem os Componentes Quilombola e Indígena, que são peças a parte ao EIA, com conteúdo determinado pelas instituições responsáveis (FCP e FUNAI) e avaliados por elas desde 2012. (http://www.funai.gov.br/arquivos/conteudo/cogedi/pdf/Boletim\%20de\%20Servicos/2012/1\%20-\%20Separata\%2001\% 20de\%2010-01-12\%20\%20(IN-Lic\%20Ambiental\%20).pdf inclusão. Isto dá um grau de autonomia, mesmo que vigiada, às etnias, e contribui para preocupações de gestores do possível insucesso de obter licenciamento.
} 
saúde indígena e com pesquisas comparativas de políticas de saúde em áreas urbanas, rurais e indígenas no final dos anos.

A Universidade estava presente em grupos indígenas, sindicatos de trabalhadores rurais, quilombos e trabalhos de gênero, reforçando ações de protagonismo. Este trabalho rebateu na CHESF. A Professora Judith Hoffnagel participou, na colaboração, do Programa Pró-equidade de Gênero e Raça, da Secretaria Nacional da Mulher (SPM), que reconhecia grandes firmas com práticas e políticas internas de emprego favoráveis à equidade de gênero e raça, com o Comité de Gênero da CHESF, muito ativo e premiado, coordenado pela psicóloga e assessora de comunicação social, Ivana Rizvi, junto à presidência. Cursos de Gênero e Diversidade na Escola, e da SECAD (Secretaria de Educação Continuada, Alfabetização e Diversidade do Ministério de Educação) e da SPM, SEPPIR e CLAM para Gestão de Políticas de Gênero e de Raça, junto com continuadas pesquisas na região.

Com outros antropólogos, havia sintonia com algumas ações muito visibilizadas também pela sua origem no Museu Nacional e pela sua atuação em amplas redes nacionais e internacionais, articuladas com o Nordeste do Brasil. A cartografia social com elaboração de cadernos descritivos do território pela própria população de moradores de um território, mobilizada em locais ameaçados por projetos privados e públicos de desenvolvimento (Acselrad, 2008; Almeida, 2020), de um lado, e o registro documental e sistematização no atlas indígena do Nordeste, desde os anos 90 (Oliveira Filho; Leite, 1993), de outro. Ambas as ações, e, em especial, a cartografia, incentivaram os indígenas a refletir sobre como ocuparam os espaços locais, e conseguiram subsidiar a documentação de tradições legitimadoras de direitos associados à identidade étnica territorial. A metodologia de registros e mapas somou muito positivamente nos repertórios confrontacionais, intersectando com o discurso ambiental tão frequentemente acionado para gestar as práticas do Estado. O Atlas contribuiu para que antropólogos formados fora do Nordeste conseguissem se integrar a programas em expansão no programa da REUNI para fortalecimento do ensino superior, e a cartografia permeou a prática de muitos docentes, independente das suas origens de formação.

Nessa conjuntura, um engenheiro arquiteto, $\mathrm{PV}^{14}$, da firma "B" que, sob diferentes denominações e respectivos CNPJs, realizava, em colaboração com Engevix e outras instituições, diversos projetos junto à CHESF, me convidou para ser o antropólogo responsável pela parte do estudo de comunidades tradicionais numa equipe do EIA, para o licenciamento da barragem de Riacho Seco, entre Itaparica e Sobradinho. PV vinha de uma experiência bem recente de desistência de uma equipe disciplinarmente mista com outros antropólogos no EIA para o licenciamento das duas barragens: Riacho Seco e Pedra Branca. Participaram professora Vânia Fialho, discentes e profissionais associados à UFPE, à UPE (Universidade de Pernambuco), ONGs promotoras de

\footnotetext{
${ }^{14}$ Uso nomes completos de antropólogos e autores públicos, e apenas uma abreviatura para outros agentes e firmas.
} 
cidadania, o CIMI (Conselho Indigenista Missionário) e o Centro Josué de Castro (com Jacirema Bernardo). A equipe alertava sobre as exigências descabidas da "B", da CHESF e do Engevix (este último, em colaboração estreita com parceiros CHESF e "B", formalmente encomendava o trabalho, para não invalidar a participação posterior da CHESF no leilão da obra). Apressados para adiantar a aprovação, pediram à equipe anterior para considerar um estudo parcial, que não abrangia por completo todas as populações, como o estudo final ${ }^{15}$. A descontinuidade desse trabalho teve, no mínimo, dois desfechos. Primeiro, com a desistência, os gestores que encomendaram o projeto decidiram dividir o trabalho (prática estratégica comum em planejamento de EIAs), retirando Pedra Branca do estudo por acharem que as demandas numerosas e taxativas dos indígenas e quilombolas, atiçados ainda mais pela inclusão no projeto de transposição e orientados por integrantes do movimento negro e projetados para serem atingidos por Pedra Branca, serviriam como impedimentos de aceitação da barragem ${ }^{16}$. O número de indígenas organizados e quilombolas na área atingida por Riacho Seco era menor e mais distante da transposição. Segundo, a estreita colaboração entre integrantes da equipe desistente, a inclusão e a nova ética apresentaram preceitos éticos coadunados, evitando que o estudo fosse encomendado a um grupo desqualificado na antropologia, sempre uma desconfiança que paira nos estudos para projetos de desenvolvimento.

$\mathrm{Na}$ equipe nova estava a antropóloga Carla Siqueira Campos, mestra da UFPE, conhecedora de povos indígenas e com estudo recentíssimo, via o Centro Luiz Freire, usando a metodologia de cartografias sociais, de demandas para inclusão social em políticas de assistência de quilombolas do sertão. Conhecia de perto as comunidades quilombolas, suas diferenças, coesão interna e reivindicação identitária. Havia mais uma dezena de integrantes, cada um nas suas áreas específicas ${ }^{17}$. Novamente sofreu entraves organizacionais na relação entre instituições encomendadoras e a firma "B" e pesquisadores, levando à rescisão do contrato com PV. Engevix continuou. Houve substituição de alguns profissionais e continuação de outros (incluindo os antropólogos) na terceira equipe, desta vez supervisionada por JDB, engenheiro ambiental experiente e ex-funcionário capacitado da CHESF (Departamento de Meio Ambiente) e uma equipe administrativa de assistentes sociais, com destacada presença de uma (LM),que depois atuou também no processo de indenização dos Truká como se vê mais adiante.

Como integrantes de uma equipe de um estudo de Impacto Ambiental, estávamos num campo multidisciplinar sob a hegemonia do discurso ambiental, que operava uma ideologia de significar

\footnotetext{
${ }^{15}$ A primeira equipe, enfrentando irregularidades administrativas, desistiu pela restrição à completude necessária do trabalho e pela restrição da normatização "ambiental" entre atingidos direta e indiretamente.

${ }^{16} \mathrm{Na}$ exclusão de Pedra Branca do plano, nesta hora, apareceram razões técnicas de riscos de assoreamento, limitados quilowatts gerados e balanço de custo e benefício para a empresa. A probabilidade de perdas provenientes de publicidade negativa divulgada pelas redes colaborativas das populações impactadas, e o risco de investimentos perdidos com ações embargatórias tiveram muita força na decisão.

${ }^{17}$ Pela lógica "meio físico, meio biológico, meio antrópico", incluí itens como biologia (fauna e flora), patrimônio, populações urbanas, economia, comunicação, socioeconômica (cadastro), entre outros.
} 
pertencimento a esferas tradicionais e/ou modernas, e de progresso e desenvolvimento. Em campo o assessor biólogo ambiental do Engevix, formalmente responsável pelo projeto, carimbava uma lógica empresarial e mais "ambiental" do que humana, ao estudo das equipes. Apresentações sobre a tecnologia horizontal projetada para gerar energia, feitas pelo JDB, ressaltavam o convencimento da viabilidade, por haver menos água represada, menos áreas inundadas e limitados impactos ambientais. $\mathrm{O}$ estudo de comunidades tradicionais evidenciou que havia uma consciência aguçada dos efeitos deletérios do controle tecnologizado da gestão de água desde as mudanças nas correntezas de água e inundação das vazantes (Sobradinho), bem como uma convivência conflituosa com os reassentados (Itaparica). Nas comunidades, circulavam pessoas e candidatos adeptos de movimentos negros (sobretudo SB, do sul do país, que formou ligações duradouras locais, agindo com mulheres e raça); outros dirigentes de pescadores tradicionais e de sindicatos rurais, e integrantes atuantes do Movimento de Atingidos de Barragens - MAB. Para eles, a ideia de baixo impacto ambiental não era confiável. A expectativa era de intensificar os danos do ambiente sentidos há décadas, agora mais diretos e imediatos. Nas comunidades ribeirinhas dos municípios de Curaçá e Santa Maria da Boa Vista, os moradores queixavam do que vinha ocorrendo desde anos atrás. Visitas dos técnicos do projeto aos locais, sem conversar, resultaram em fincar marcadores físicos de previsão de enchimento do reservatório em ocasiões e níveis diferentes, conforme as mudanças nas especificações técnicas previstas das turbinas. Ia aumentando a incerteza sobre perdas futuras e articulando uma miríade de agentes da resistência à barragem, contando com a documentação solidária dos antropólogos do estudo.

Mais uma vez, entre as coisas que mais incomodavam os antropólogos, estava o desenho técnico que dividia a área atingida em "diretamente atingida" e "indiretamente atingida", de uma linha traçada na medição de três quilômetros da beira do rio, sem orientação por acidentes geográficos nem por histórias de ocupação e uso humano geograficamente interconectados. Falseava grosseiramente os reais impactos: um ambiente interconectado, fragmentado por decisão técnica sobre o uso desejado dos recursos hídricos para geração de energia.

Não era apenas a incerteza sobre os impactos ambientais que incomodava as comunidades. Era inquestionável que a área a ser atingida pelas águas de Riacho Seco estava com grupos indígenas e quilombolas em menor quantidade que na área de Pedra Branca, retirada do estudo. Em Pedra Branca, o povo indígena Truká, na Ilha de Assunção, e o povo Tumbalala, em Abaré/Curaçá da Bahia, estavam às voltas com efeitos de outros projetos: uma linha de transmissão na ilha e reassentados em projeto nos solos mais férteis (ambos de Itaparica), bem como a transposição das águas do Rio no lado ocidental da Ilha.

A CHESF imaginar que restringir o estudo à barragem de Riacho Seco porque não haveria um movimento organizado e reivindicativo de identidade étnica era um engano. Atiçado em boa parte 
justamente pelas intervenções desenvolvimentistas energéticas históricas na região que reconfigurava os seus domínios territoriais, um trio de comunidades quilombolas (Serrote, Inhahuns e Cupira) na beira do rio e próximo a ela (portanto direta e indiretamente atingidos) morava onde seria o canto de obras para a barragem. Todas estavam conectadas nas redes que protagonizam identidade quilombola, do MAB e de consciência de gênero com liderança feminina reconhecida (Ferretti, 2013, Souza 2017; Melo, 2016). Estavam ativamente gerenciando os seus direitos territoriais (junto à Fundação Cultural Palmares e ao INCRA) e comunicavam com outras comunidades que iniciavam ações semelhantes no lado baiano, junto com lideranças políticas locais, como em Nova Jatobá. Recusaram realizar o cadastro proposto pelos planejadores, opondo-se à inclusão. Também havia populações indígenas dispersas e pouco numerosas com figuras de liderança notáveis, separadas fisicamente, mas ainda ligadas aos seus grupos de origem. O mais expressivo dos grupos indígenas, altamente questionado na sua legitimidade pela administração geral do EIA e por partes da comunidade local, relacionado, nas origens, com o povo Atikum mais ao leste e norte com as quais tinham parentesco e afinidade, ocupava uma fazenda em falência no lado baiano ${ }^{18}$.

O extenso relatório sobre populações tradicionais no EIA documentava impactos sobre populações ribeirinhas, cuja memória histórica de muitas gerações não se traçava pela etnicidade, mas incluía uma consciência ambiental significativa e de proteção aos seus espaços de vida (Escobar, 2008). Incluía detalhes sobre movimentos sindicais dispostos a continuar a resistência a barragens; comunidades de pescadores artesanais prejudicadas por mudanças na fauna do rio desde Sobradinho; quilombolas e indígenas engajados em redes de protagonismo identitário, com uma vigilância cuidadosa das ações do Estado, tanto para se legitimar, quanto para se proteger de incursões nos seus territórios. Seus territórios não se configuravam como espaços que priorizavam produção e lucro na competição para o uso dos recursos locais. Documentavam a disputa sobre de quem é o ambiente, de como será gerido, amplamente informada por décadas de história, políticas sociais governamentais, e redes articuladas como um conjunto de opositores ferrenhos aos danos ambientais e impactos sociais de uma nova intervenção no Rio São Francisco. O fato de essas populações indígenas, quilombolas e ribeirinhos terem suas moradias no ambiente local como um espaço para viver subsidia uma diferenciação "moral”" em oposição àqueles que desejassem que os seus espaços de moradia fossem convertidos em espaços subsidiários à produção de energia.

Nas etapas finais do trabalho, a equipe do EIA, na sede da CHESF, com assessores externos convidados pela coordenação, em conformidade com a legislação, foi convidada a sugerir ações mitigadoras, cada profissional dentro da sua área de especialidade, pelos impactos previstos nos seus

\footnotetext{
${ }^{18} \mathrm{O}$ fato desse grupo indígena ocupar uma fazenda falida foi alvo de crítica dos seus detratores, que os comparavam aos numerosos grupos de sem-terra que, na região, também ocupavam fazendas em falência, com mais frequência no lado pernambucano.
} 
estudos. Além de constar no EIA, serviriam para subsidiar o RIMA levado para discussão obrigatória em audiência pública com a população. A discussão das ações mitigadoras durou vários dias com apresentações e discussões, e a equipe antropológica gerou uma lista longa de sugestões, precedida por dois pedidos de mitigação no caso de não haver aprovação da obra - reparação de danos criados pelo ambiente psicologicamente inóspito, produzido ao longo das décadas de preparação técnica, prevendo a sua construção, e uma redistribuição das prioridades de tecnologias de geração de energia dentro da empresa devido às dimensões dos danos e ao esgotamento de potencial hídrico para gerar energia no Rio São Francisco e prejuízos a comunidades tradicionais.

Nenhum antropólogo foi convidado a nenhuma audiência pública. A versão final do trabalho de comunidades tradicionais do EIA sofreu um corte silencioso de mais de 50 páginas de etnografia documentando as tensões e sofrimento ocorridos a ribeirinhos, pescadores, quilombolas e indígenas devido a mudanças ambientais anteriores e sua contribuição a uma presença generalizada de inquietação e hostilidade aos planos de mudança do seu ambiente. Reparamos o corte da nossa redação, com expectativa de boa capilaridade, enviando os relatórios originais, sem corte, às lideranças e pessoas dos povos da região para tornar conhecido a nossa posição e a documentação feita. Até hoje não houve aprovação em audiência pública. E não houve licenciamento ambiental, um ponto de orgulho das comunidades organizadas da comunidade para quem construímos e geramos informações e solidariedade de muitas maneiras ${ }^{19}$, incluindo o acréscimo das mitigações de não aprovação do licenciamento e a disseminação da versão completa do relatório, levando a incomodar planejadores e gestores.

Ilha de Assunção

Em 2012, três anos depois do EIA de Riacho Seco, "N", outra firma que realiza estudos encomendados pela CHESF e outras instituições, instada pela atuação do Ministério Público, contratou antropólogos porque a CHESF legalmente teve que ter alguém habilitado junto ao IBAMA para fazer a parte antropológica do "Estudo dos Impactos Socioambientais e de Valoração Econômica dos Danos Ambientais Causados pela Passagem da Linha de Transmissão Cabrobó/Pedra Branca 69kv na Terra Indígena Truká”. O diretor da firma, AA, engenheiro sanitarista aposentado da CHESF, era especializado em gestão de águas e serviços de consultoria, quase sempre para a própria CHESF. Nesse estudo, teve apoio de dois jovens especialistas em estudos ambientais: PB (biólogo, cientista ambiental) e SH, bióloga, (engenheira ambiental). Os antropólogos, conhecedores da região, ficaram

\footnotetext{
${ }^{19}$ Ferretti (2013) elaborou uma dissertação detalhada sobre a resistência a Riacho Seco e à aplicação de legislação ambiental, documentando exemplificações de práticas de dissimulação e desrespeito sobre o que chamamos de "táticas de desmonte", organizadas por empreendimentos ansiosos para aprovar os projetos para produzir os seus produtos e ludibriar os atingidos.
} 
responsáveis pelo estudo "ambiental” da população indígena. Havia dois outros especialistas para coordenar relatórios das mudanças do meio biológico e do meio físico, bem como dois economistas encarregados de transformar todos os danos em cifras para a parte de "valoração econômica". A decisão favorável do Ministério Público do pleito instaurado pelas lideranças indígenas, com certa autonomia em relação à FUNAI, mostrava a maturação do momento histórico do Vale do Rio São Francisco, em sintonia com as políticas vigentes nacionais, de aplicar demandas ambientais respeitando algumas questões de identidade étnica em ações protagonizadas pelos próprios grupos étnicos. Na Terra Indígena da Ilha de Assunção, localizada dentro da área que iria ser atingida pela barragem de Pedra Branca (ou seja, a parte retirada do EIA de Riacho Seco), uma linha de transmissão tinha sido erigida para fornecer energia ao projeto de reassentamento Pedra Branca, para atingidos de Itaparica, desde trinta anos antes. A derrubada da torre de transmissão no projeto da CHESF, construída nas terras mais férteis dos Tumbalala, demonstrou o ressentimento histórico e ativo em relação à incursão da CHESF sobre os seus domínios. No outro lado da linha de transmissão, que passou pela Ilha de Assunção, outra torre de transmissão, menor, foi derrubada numa ação combinada de revolta contra a CHESF e de disputas com lideranças não-indígenas, no município de Cabrobó. A ação movida pela liderança indígena junto ao Ministério Público foi ganha, e reconhecida formalmente pela CHESF, com direito à "Indenização Residual” aos danos nas suas terras como população atingida. Longe de ser uma demanda do setor elétrico para conseguir produzir e vender mais energia, esta ação foi um reconhecimento formal da responsabilidade de indenizar, e medo de futuras derrubadas de torres. A questão foi de dimensionar os danos e calcular o valor para pagar ao povo Truká. Lembrava a imagem imponente de uma torre de transmissão na capa original da dissertação em antropologia da UFPE, “A Besta Fera e as Águas de Baixo” (Silva Filho, 1992 ${ }^{20}$ ), de um integrante da equipe do estudo de Itaparica, relatando a demonização do processo de reassentamento nas representações do povo atingido desde aquela época!

A equipe desta vez era menor que as outras vezes. Os especialistas em meio físico e no meio biológico realizaram estudos cuidadosos do uso de solo, de vegetação e da fauna na ilha num roteiro próprio de atividades. $\mathrm{Na}$ equipe de pesquisa antropológica, houve uma estudante de graduação em direito que estudou a retomada das terras Truká, Gabriela Andrade ${ }^{21}$. No NEPE, professores Athias e Fialho tinham orientado mestrandas que produziram conhecimento sobre os Truká, mas não integraram a equipe. A mestra orientada por Prof. Schröder, então doutoranda em sociologia, Eliana de Barros Monteiro ${ }^{22}$, concursada na UNIVASF, capacitada e integrada com o povo Truká (Monteiro, 2008), trouxe com ela três alunos de graduação para a pesquisa: Thainã Barros, Eliane da Silva

\footnotetext{
${ }^{20}$ Orientada pela Profa. Gisélia Potengy.

${ }^{21}$ Aluna de graduação em direito, orientada pelo autor. Depois ingressou no Programa de Pós-Graduação em Sociologia.

22 Orientada por Prof. Paulo Henrique Martins e coorientada por Vânia Fialho.
} 
Ferreira e Rodrigo Wanderley. PB, com sensibilidade para questões sociais e prática em consultoria ambiental, acompanhou a pesquisa de campo. Fazia a ponte entre as equipes e o atuante diretor AA. Os economistas entraram depois da identificação dos danos ambientais pelas equipes para calcular valores. Pela CHESF, houve integrantes do Departamento de Meio Ambiente que participaram em algumas reuniões com a equipe e com a comunidade, incluindo a assistente social, LM, figura conhecida no trabalho anterior do EIA de Riacho Seco.

O estudo ambiental trouxe o desafio de compreender um ambiente de ilha que fazia parte de um arquipélago no Rio São Francisco. A Ilha de Assunção é a maior (quase trinta quilômetros em extensão), com diferentes usos do solo para plantio e criatório com diferentes tecnologias), bem como vegetação nativa como áreas preservadas e tanques de criação de peixes. A pesca artesanal foi notavelmente debilitada depois das mudanças nos fluxos de água devido à presença das barragens. Os sete quilômetros de linha de transmissão passaram por cima de diversas áreas de plantio na parte oriental da ilha, passando para o lado baiano e seguindo quilômetros adentro na caatinga até chegar no assentamento de Pedra Branca. A presença da linha exigia o controle de distâncias e das alturas de alguns tipos de plantio e limitava a presença de animais para pastar. Ela representava um elemento estranho na comunidade porque saía da subestação da CHESF em terra firme, em Cabrobó, passava pela terra indígena, mas não trazia energia à população local, e sim ao povo no reassentamento compensatório de Itaparica, distante a dezenas de quilômetros sertão adentro, fincada na terra dos parentes indígenas, Tumbalala.

A leitura étnica desta presença da linha no ambiente local é mais profunda que simples restrições de uso localizado comum a linhas de transmissão. Os Truká nunca tinham recebido um centavo pela desapropriação dos espaços para construção das linhas e pelos danos sofridos, não porque a CHESF se recusava a indenizar populações atingidas, mas porque a indenização foi paga a posseiros não-indígenas que, na hora da construção, criavam e plantavam na Ilha depois de expulsar os indígenas através de operações de venda que particularizavam a terra, e de ações truculentas repetidas que forçavam a população indígena a ficar refém em esconderijos em outras ilhas ou em áreas de terra firme onde encontravam maior acolhida. A CHESF, com a decisão do Ministério Público, reconhecia que a Ilha era, de direito, dos indígenas, que haviam retomado a Ilha à força, numa série de ações de 1994 até o início dos anos 2000. O relatório de reconhecimento histórico foi elaborado pela antropóloga Mércia Batista, da UFCG (Batista, 2004); Além de outros conteúdos, o relatório documenta duas coisas: o uso histórico e identificação com espaços historicamente sagrados da Ilha e dos matos preservados que eram os ambientes reconhecidos dos ancestrais espirituais e suas forças na cosmologia étnica; e os meios ilegítimos usados pelos posseiros para se apossar da terra alheia. Foi essa documentação (de reconhecimento e de estudos de Universidades) que fundamentou a decisão do Ministério Publico favorável aos Truká e que orientou as conversas com eles em campo, 
permitindo identificar um elenco de danos e pedir cálculos sobre eles à equipe de valoração econômica. Uma vez retomada a Ilha, os Truká conscientemente construíram reforçadores da continuidade da sua memória na forma de práticas rituais, produção de material pedagógico sobre a história indígena local, proteção das matas sagradas, e a formação de um Museu próprio que ajudava a fomentar, bem como ser fomentado, por uma liderança forte.

O desfecho da intervenção poderia ter sido mais favorável. Até agora o povo Truká não recebeu o valor que a equipe calculou. Desconfianças sobre as intenções da CHESF tinham sido levantadas numa reunião técnica reservada da equipe e de técnicos da CHESF, sobre a lógica de calcular os valores. Achando que o nosso cálculo superestimava o valor ao qual os indígenas tinham direito, um técnico falou que pelas práticas do Sistema Eletrobrás, o valor indenizatório para qualquer grupo indígena não passava de cinco milhões de reais ${ }^{23}$ ! Justificamos nossos cálculos, expondo com clareza cada elemento. Os relatórios todos foram recebidos pela CHESF para tomar as devidas providências. Até hoje não se apresentaram justificativas técnicas pelo não encaminhamento da parte final do trabalho junto ao Ministério Público e o pagamento da indenização, e as nossas reivindicações de agilização estão sem surtir efeitos.

Algumas Observações sobre Ambiente e Etnicidade

Retomar o debate sobre justiça ambiental e insistir na importância da consideração de reivindicações dos grupos étnicos situados em locais atingidos por barragens seria revisitar argumentos muito bem estabelecidos (Acselrad, 2008; 2010; Almeida 2018; Almeida et. al., 2020; Bursztyn, 2001; Little, 2010; Ribeiro, 1991; Zhouri et. Al., 2005; Zhouri, 2013; Teixeira et. Al., 2020; Vainer e Araújo, 1991; Duque, 1982; Ferreti, 2013; Silva, 1997; Oliver-Smith, 1991; Vianna, 1992; Bronz, 2013, MAB, 2013) que fogem da abrangência deste trabalho. Para acrescentar um reforço ao posicionamento sobre como o ambiente se insere nas práticas de negociação de grandes empreendimentos, Abramovay (2019) argumenta que rege uma economia de destruição que sintetiza a natureza em produtos mercantilizáveis em circuitos de negociações que fornecem ganhos de escala para os empreendedores. E ressaltando o mascaramento das consequências, Teixeira et. al. (2020, p. 3) definem como uma "economia de visibilidades" que encobre deslocamentos múltiplos e violações à população através de procedimentos técnicos direcionados a delinear e gerir territórios.

Este trabalho é uma compreensão etnográfica e historicamente informada sobre como, num conjunto específico de processos de negociação nos quais eu me envolvi como antropólogo,

\footnotetext{
${ }^{23}$ Neste comentário, transparecem atitudes de muitos planejadores e gestores diante de indígenas e estudos de antropólogos. Mesmo com sólidas justificativas de impactos prejudiciais, as demandas que ultrapassam a expectativa da empresa são refutadas, quando não taxadas de caluniosas. Na logica empresarial, os componentes indígenas/quilombolas devem se ajustar aos interesses da empresa, e não produzir as informações que a legislação preconiza.
} 
configura-se uma transformação na relação entre empresa e atingidos com referência a práticas e uso de discursos sobre ambiente e sobre etnicidade. Algumas das seguintes observações são elegantemente analisadas em quadros sintéticos por colegas que escrevem sobre estes processos. Certamente tiveram influência no meu olhar. Não volto a estes autores, nem introduzo outros, fechando com observações pontuais sobre convergências e divergências nas três experiências relatadas no foco ambiente/etnicidade num período de quatro décadas no Rio São Francisco.

Moralidade Técnica: através de uma moralidade técnica ${ }^{24}$ operada pela CHESF, como Instituição operadora responsável por obras relacionadas com a geração de energia de fontes hidráulicas, a ideia de ambiente é uma ferramenta para englobar etnia. A sua adesão aos ditames de documentos oficiais para orientar as suas ações informa que o que se precisa avaliar e gestar é o ambiente. O próprio nome da empresa - Companhia Hidro Elétrico do Vale do São Francisco circunscreve ambientalmente o seu raio e objeto de ação. Quando aciona uma equipe multiprofissional para aperfeiçoar tecnicamente cada objeto ou situação enfrentada, todos precisam apresentar as suas ideias para conformar a prática moldurada pela legislação que prioriza o ambiente. É pressuposto que comunidades tradicionais, ribeirinhos, quilombolas e indígenas fazem parte do ambiente a ser controlado e mudado pela CHESF, com pouca percepção deles como construtores interativos com o meio em permanente fluxo na sua relação com as pessoas que aí vivem. Criada no período pós-guerra de euforia desenvolvimentista e agindo num planejamento de um conjunto de obras agilizadas durante a ditadura militar, a organização técnica esmerada de setores de engenharia da CHESF abre pouco espaço para lidar com um processo multifacetado de democratização que visa às demandas de identidades e usos locais de ambiente de grupos de pessoas com uma cidadania reforçada em políticas sociais de reconhecimento desses grupos, suas identidades e seus ambientes locais. Ela se enxerga como respondendo às demandas de fornecimento de energia como produto para alimentar o crescimento.

Equipes Multiprofissionais: ao repetir a prática de estabelecimento de contratação de equipes multiprofissionais, remete o poder decisório geral a um nível gerencial e técnico que está altamente comprometido com os objetivos de implantação do projeto, consciente de estar licenciando ou mitigando, muito mais de que refletindo sobre a viabilidade ou aconselhabilidade do projeto em si. Quando os gestores são contrariados com recomendações de profissionais especialistas, mesmo bem fundamentadas, as práticas revelam um repertório múltiplo de caminhos para escamotear/ invisibilizar os potenciais resultados negativos percebidos pelos especialistas. Estas priorizam buscar o alcance da aprovação do projeto técnico. Assim, recorre a: insistência em modificar as recomendações, excisões de trechos que desagradam, alegação de entraves técnicos ao

\footnotetext{
${ }^{24}$ Este conceito está mais elaborado por mim num artigo no prelo, a ser publicado por Roberto Lima da UFSE. 
prosseguimento do trabalho, questionamento ou desmoralização das fontes de informação, trocas de profissionais responsáveis e diversas outras táticas. Não raramente o alvo de tais práticas são as percepções de grupos étnicos atingidos, ou a serem atingidos, por serem partes reflexivas e cognoscentes do ambiente, junto aos antropólogos que reportam suas representações.

História e Políticas Sociais: a história é uma implacável transformadora (devo usar uma palavra menos elétrica!) da realidade. Mesmo com o aperfeiçoamento técnico das exigências de Estudos de Impacto Ambiental, sua capacidade de congelar os determinantes das relações de negociação de uma forma sincrônica foge a tais possibilidades técnicas. Um estudo de "impacto", evidentemente é diacrônico em parte do seu foco. Condições conjunturais são criadas através de políticas públicas e de agentes promotores de mudanças, em especial, associadas a ideias de equidade e de direitos. As políticas do período democrático pós-constituição abriram brechas e continuaram abrindo (apesar de contratempos regressivos eventuais) para o discurso de identidade étnica e direitos daí decorrentes, permitindo a ampliação da articulação por diversos meios em redes internacionais, nacionais e regionais. Tais eventos contribuem para os repertórios confrontacionais em ações de oposição a projetos e à negociação de mitigação por danos aos atingidos. A própria palavra "mitigação" presume o sucesso do licenciamento, criando uma hierarquização de valor prévio que pode, de fato, ser revertida quando a conjuntura política é favorável. De 1988 a 2014, em cada uma das experiências vistas, são muitos os caminhos para o não tão paulatino reconhecimento formal e estímulo a práticas sociais e jurídicas que reforçam identidade étnica, diversidade, equidade e diferença, inseridas num contexto histórico nacional e internacional favorável. Da fragmentação e escorraço de grupos indígenas para locais mais distantes, e da anulação da identidade negra percebidos no reassentamento em Itaparica, concebido no período pré-constituição de 1988, passa-se por uma série de ações posteriores que criam instâncias de reconhecimento e legitimidade ao nível federal e meios de operacionalizá-las. As resistências a ações nocivas contra populações locais se fortalecem. Populações tradicionais não são isoladas. São articuladas com redes diversas, e ainda respaldam legalmente retomadas de territórios indígenas e quilombolas injustamente afastados das suas moradias históricas.

Crescimento da Universidade: integralmente relacionados ao conjunto de ações referidas no item acima, e merecedor de um realce particular por ser o âmbito principal da formação para a labuta antropológica, o crescimento da universidade, bem como de outras instâncias educacionais e de capacitação para políticas públicas, contribuiu para uma "massa crítica" capaz de visibilizar e interagir com grupos étnicos de uma forma dinamizada. Talvez, diria como pertencente a um grupo de antropólogos, "engajados e afetados" com e pelos povos com quem (mais de que sobre quem) estudamos! O crescimento exponencial de trabalhos de conclusão de curso, dissertações, teses, atlas, mapas, cadernos, museus, material pedagógico, profissionais e técnicos nativos, núcleos de pesquisa, 
etc., todos juntos, alavancam a produção de muito conhecimento sintonizado e em interação colaborativa na defesa dos direitos étnicos. A interação com diversas instâncias coletivas não governamentais e de movimentos sociais preocupados com cidadanias situadas, como vistas aqui (CIMI, Polo Sindical, Centro Luiz Freire, movimentos negros, associações indígenas, grupos feministas, etc.) é peça fundamental na defesa de populações atingidas. Espaços acadêmicos têm sido muito reforçadores, inclusive na formação não somente de organizações não governamentais atuantes, mas também das próprias associações de indígenas, quilombolas, de pescadores, e de outros grupos (mulheres, LGBTTQ, bio-identidades, etc.) nos quais a "interseccionalidade" atribui um elemento étnico e racial fortalecedor dos seus propósitos. É importante ressaltar que o espaço de estudos, por mais importante que seja, nem supera nem substitui o que os próprios grupos organizam e articulam para que sejam vistos e ouvidos.

Astúcias dos Poderosos: a existência de redes articuladas com as próprias comunidades tradicionais e a presença de antropólogos em universidades de referência próxima e integrada às populações com colaborações diversas a favor da equidade e da diversidade resultam num trabalho cuja credibilidade precisa ser constantemente recriada e reconfirmada, pois o grau de desconfiança de populações atingidas e de grupos que os defendem levantada por pesquisas encomendadas por instituições gestoras de grandes projetos está merecidamente elevado diante das astúcias dos poderosos. Cria-se questionamentos dentro do Estado contra as suas próprias instituições defensoras de grupos tradicionais, vulneráveis e do ambiente. Isso requer do profissional de antropologia uma autovigilância permanente relacionada às instâncias de formação e de compartilhamento de ideias em debates coletivos organizados em fóruns disciplinares e extradisciplinares.

É preciso sempre alertar sobre a continuidade do exercício de subterfúgios institucionais, realizadas em bastidores institucionais, que visam a reinserir o pleno controle ambiental e interrelacional para os detentores e idealizadores dos projetos. Com todas as forças a favor de identidades étnicas com repertórios variados e fortes, uma negociação é uma negociação onde existe fricção e confrontação que sempre oferece a possibilidade do segredo e da dissimulação, por mais formalizada e pública que possa ser a arena da disputa. O que pode imperar em domínios de poder em confrontação pode ser a reificação do controle firme sobre o respeito ao ambiente na sua forma instituída e hierarquicamente diferenciada, o que pode implicar, de fato, que, além de haver um ambiente não respeitado, as práticas de desenvolvimento se erguerem sobre um desrespeito e evitação de etnicidade, quando deixar brecha.

\section{REFERÊNCIAS}


ABRAMOVAY, Ricardo. Amazônia: por uma economia do conhecimento da natureza. São Paulo: Elefante, 2019.

ACSELRAD, Henri. Grassroots reframing of environmental struggle in Brazil. In: CARRUTHERS, David (ed.) Environmental Justice in Latin America, Cambridge: MIT Press, 2008.

ACSELRAD, Henri. Ambientalização das lutas sociais - o caso do movimento por justiça ambiental. Estudos avançados., São Paulo, v. 24, n. 68, 2010. Disponível em:

$<$ http://www.scielo.br/scielo.php?pid=S0103-40142010000100010\&script=sci arttext $>$. Acesso em: 10 jun. 2020.

ALMEIDA, Alfredo W. B.de. Mapas e museus: uma nova cartografia social. Ciência e Cultura, v. 70, p 58-61, 2018.

ALMEIDA, Alfredo W. B. de; ACEVEDO MARIN, Rosa; LOPEZ, J. (Org), Megaproyectos, actos de Estado, pueblos y comunidades tradicionales. Cali: Col.: Universidad Autónoma de Occidente, 2020.

ARAÚJO, M. L. C. de; CALDAS NETO, M.; LIMA, A. E. V. (org.)., Sonhos submersos ou desenvolvimento? impactos sociais da barragem de Itaparica. Recife: Massangana, 2000.

BARBIERI, José C. Avaliação de Impacto Ambiental na Legislação Brasileira. Revista de Administração de Empresas, v. 35, n. 2, mar/abr, p. 75-85, 1995.

BATISTA, Mércia R. R. O desencantamento da aldeia: exercício antropológico a partir de relatório circunstanciado de identificação e delimitação da Terra Indígena Truka. Revista de Estudos e Pesquisas (Fundação Nacional do Índio), Brasília, v. 1, n.2, p. 157-248, 2004.

BEZERRA, Tercina M. L. B. O Quilombo Negros de Gilu em Itacuruba: Emergência Etnoquilombola e Territorialidade. Recife 2007.. Dissertação de Mestrado PPGA:UFPE, 2007.

BRONZ, Débora. "'O Estado não sou eu'. Estratégias empresariais no licenciamento ambiental de grandes empreendimentos industriais." Campos v. 14, n. 1-2, p. 337-355, 2013. Disponível em: $<$ http://dx.doi.org/10.5380/campos.v14i1/2.42472>. Acesso em: 10 jun. 2020.

BURSZTYN, Marcel (org.)., A difícil sustentabilidade: política energética e conflitos ambientais. Rio de Janeiro: Garamond, 2001.

CERNEA, Michael. (ed.). Putting people first: Sociological variables in rural development. Washington: World Bank, Second Edition, 1991.

CHESF (Companhia Hidreléctrica do São Francisco). Reservatório de Itaparica: Plano de Desocupação. Recife: CHESF-CIDIR, 1985.

DUQUE, Ghislaine. "A experiência de Sobradinho: problemas fundiários colocados pelas grandes barragens." Ciência e Cultura, v. 35, n. 8, p. 1054-1061, 1982.

ESCOBAR, Arturo. Territories of Difference: place, movements, life, redes. Durham: Duke., Durham, 2008.

FERRETI, Michelle. Quando as lutas sociais reinventam a participação no licenciamento ambiental: o caso das hidrelétricas de Riacho Seco e Pedra Branca. Rio de Janeiro, RJ. 2013. Dissertação (mestrado)em Desenvolvimento, Agricultura e Sociedade, UFRRJ, 2013.

GONÇALVES, Glaciene M da S; SILVA, Edson; SCOTT, Russell P; GURGELurgel, Idê G D; COSTA, André M. "A transposição do Rio São Francisco e a saúde do povo Pipipã, em Floresta, Pernambuco." Saúde e Sociedade, 2018.de (online) v. 27, n. 4, p. 909-921. DOI 10.1590/S010412902018170388

GRIMALDI, Lorenzo. Donos da história: estratégias de ação coletiva e formação da autoridade política entre os Tumbalalá. Recife, 2013, dissertação de mestrado PPGA:UFPE, 2013. 
LITTLE, Paul. A Política Brasileira da Ecologia Política: Aspectos Antropológicos. In: MARTINS, Carlos B. (coord geral); DUARTE, Luis F. D. (coord antropologia). Horizontes das Ciências Sociais no Brasil: Antropologia, São Paulo: ANPOCS/Discurso/Barcarola, 2010.

MACHADO, Eduardo P. (Coord.) Poder e Participação política no Campo. São Paulo: CERIFA/CAR/CEDAP/CENTRU, 1987.

MAB - Movimento de Atingidos por Barragens. Política Nacional de Direitos das Populações Atingidas por Barragens, São Paulo, 2013.

MELO, Maria J. Ribeirinhos do São Francisco e a Resistência frente a Construção da USINA Hidrelétrica de Riacho Seco: O Caso do Município de Santa Maria da Boa Vista/PE,. Revista Rural \& Urbano, v. 01, n. 01, p.205-213, 2016.

MONTEIRO, Eliana de B. Eu já vi água ir embora(...) com natureza não se mexe'Os Truká (PE), grandes projetos e o sentido da territorialidade no exercício da cidadania indígena contemporânea. Recife, 2008. Dissertação de mestrado PPGA:UFPE, 2008.

OLIVEIRA FILHO, João P de. Uma etnologia dos “índios misturados”? Situação colonial, territorialização e fluxos migratórios. in: OLIVEIRA FILHO, João P. (org.) de. A Viagem da Volta: etnicidade, política e reelaboração cultural no Nordeste Indígena. Rio de Janeiro: Contra Livraria/LACED, 1999.

OLIVEIRA FILHO, João P. de; LEITE, Jurandyr. (coord). Atlas das Terras Indígenas no Nordeste. Rio de Janeiro: PETI/Museu Nacional, 1993.

OLIVER-SMITH, Anthony. Involuntary Resettlement, Resistance and Political Empowerment. Journal of Refugee Studies, v. 4, n. 2, p. 132-149, 1991. https://doi.org/10.1093/jrs/4.2.132

PANDOLFI, Maria Lia. Na Margem do Lago: um estudo sobre o sindicalismo rural. Recife, 1986: Dissertação de Mestrado do PIMES, UFPE, 1986. (republicado como livro de Araújo, Massangana, 1990).

RIBEIRO, Gustavo L. Ambientalismo e desenvolvimento sustentado e nova ideologia: utopia de desenvolvimento. Revista de Antropologia, v. 34, p. 59-101, 1991.

SÁ, Maria Auxiliadora Ferraz de. Dos velhos aos Novos Coronéis (um estudo das redefinições do coronelismo. Recife, 1974. Dissertação de mestrado PIMES:UFPE, 1974.

SIGAUD, Lygia. Efeitos Sociais de grandes projetos hidrelétricas: as barragens de Sobradinho e Machadinho. Rio de Janeiro: PPGAS/Museu Nacional-UFRJ, 1986.

SILVA, Avanildo Duque de. O reassentamento Rural de Itaparica: conflitos e transformações no espaço agrário do Submedio São Francisco - Bahia/Pernambuco. Recife, 1997. Dissertação de Mestrado em Geografia, UFPE, 1997.

SILVA FILHO, José de Carvalho, A Besta-Fera e As Águas de Baixo: um estudo de representações. Recife, 1992. Dissertação de mestrado Mestrado em antropologi: UFPE, 1992.

SOUZA, Elaine Lopes. Narradoras do Batuque: Protagonismo e Identidade no Quilombo do Serrote. Brasília, 2017. Dissertação de Mestrado em Desenvolvimento Sustentável: UNB, 2017.

TEIXEIRA, Raquel O. S.; ZHOURI, Andréa; MOTTA, Luana D. (2021), Os estudos de impacto ambiental e a economia de visibilidades de desenvolvimento., e3610501. Epub June 15, 2020. https://doi.org/10.1590/3610501/2020.

TILLY, Charles. Contentious performances. Cambridge: Cambridge University Press, 2008.

TSING, Anna. Friction: An Ethnography of Global Connection. Princeton University Press, Princeton, NJ, 2004. 
VAINER, Carlos; ARAÚJO, Frederico G. B. de. Grandes Projetos hidrelétricas e desenvolvimento regional. Rio de Janeiro: CED - Centro de Documentação e Informação, 1992.

VIANNA, Aurélio; MENEZES, Laís. Políticas de desenvolvimento no Vale do São Francisco: $O$ Pólo Sindical e a luta dos atingidos pela barragem de Itaparica. Rio de Janeiro:

CEDI/KOINONIA, Pólo Sindical do Submédio São Francisco,1994.

WORLD BANK. World Bank approaches to the environment in Brazil: a review of selected projects Vol IV: The Mmiddle and Lower San Francisco Valley. Washington: Operations Evaluation Department, 1992 (Restricted Access Report No. 10039).

ZHOURI, Andrea (org). As tensões do lugar: hidrelétricas, sujeitos e licenciamento ambiental. Belo Horizonte: Ed. UFMG, 2011.

ZHOURI, Andréa; LASCHEFSKI, Klemens; PEREIRA (orgs.). A insustentável leveza da política ambiental-Desenvolvimento e conflitos socioambientais. Belo Horizonte: Autêntica, 2005. 